\title{
ECG Body Surface Mapping in Patients With Gestational Diabetes Mellitus and Optimal Metabolic Compensation
}

\author{
E. ŽÁKOVIČOVÁ ${ }^{1,3}$, O. KITTNAR ${ }^{2}$, J. SLAVÍČEK $^{2}$, E. MEDOVÁ ${ }^{2}$, P. ŠVÁB ${ }^{3}$, \\ J. CHARVÁT ${ }^{3}$
}

${ }^{1}$ Diabetology and Endocrinology Outpatient Clinic Service Hospital Medissimo, Bratislava, Slovak Republic, ${ }^{2}$ Institute of Physiology of the First Faculty of Medicine, Charles University, Prague, ${ }^{3}$ Medical Department of the Second Faculty of Medicine, Charles University, Prague, Czech Republic

Received March 11, 2014

Accepted July 7, 2014

\begin{abstract}
Summary
Women with gestational diabetes mellitus (GDM) are at increased risk for cardiovascular diseases (CVD) events compared with women without GDM. The aim of the present study was to evaluate 200 parameters of the heart electric field in 35 women with GDM under optimal glycemic compensation compared to 32 healthy pregnant women. All examinations were performed in the 36th week of gestation. The parameters in ECG body surface mapping (BSM) were registered by the diagnostic system Cardiag 112.2. The absolute values of maximum and minimum in depolarization and repolarization isopotential, isointegral and isoarea maps were not significantly different between the groups. These findings correspond to the result of heart rate variability examination. However BSM revealed the significant prolongation of QRS complex $(p=0.05)$, shortening of ventricular myocardial activation time (ICHVAT) $(p=0.01)$, prolongation of mean QT duration $(p=0.01)$ and increase of $Q T$ interval dispersion $(p=0.01)$ in women with GDM. Duration of QRS and ICHVAT significantly correlated with interventricular septum and posterior wall thickness in GDM group, QTd interval correlated significantly with $\mathrm{HbA1C}$ level. We conclude that despite of optimal metabolic control several significant abnormalities detected by ECG BSM are still present in patients with GDM.
\end{abstract}

\section{Key words}

ECG Body Surface Mapping - Echocardiography - Heart rate variability • Gestational diabetes mellitus

\section{Corresponding author}

O. Kittnar, Institute of Physiology, $1^{\text {st }}$ Medical Faculty, Charles University, Albertov 5, 12800 Prague 2, Czech Republic. E-mail: okittnar@lf1.cuni.cz

\section{Introduction}

Gestational diabetes mellitus (GDM) is defined as carbohydrate intolerance of varying degrees of severity with onset or first recognition during pregnancy (Metzger and Coustan 1998). The incidence of GDM occurs in about 3-5\% of all pregnancies and it is often associated with maternal risk factors such as overweight, advanced age, positive family history of DM type 2 and a previously complicated obstetric history. GDM is also associated with a high risk of subsequent development of maternal diabetes later in life (Bellamy et al. 2009, Feig et al. 2008, Kim et al. 2002) and cardiovascular disease (Sullivan et al. 2012).

ECG body surface isointegral, isopotential and isoarea maps (BSM) are the sensitive indications of local electrical depolarization and repolarization changes. Some works with ECG BSM in patients with diabetes mellitus type 1 showed significant changes in the QT interval and QT dispersion - QTd (Palova et al. 2010, Zdarska et al. 2007). Several changes of the electrical heart field have also been observed in healthy women in the high phase of physiological pregnancy. They can be explained by changed spatial arrangement of the chest organs during pregnancy (Lechmanova et al. 2002). This methodics enables detection of pathological electrocardiographic changes in early degree and subsequent detection of the presence and extent of cardiovascular risk. It has already been used in patients with GDM and revealed significantly higher average QT dispersion in GDM women (Medova et al. 2012). The 
dispersion of QT interval seems to be important in detection of repolarization abnormalities and might be responsible for rhythm disorders (Cowan et al. 1988, Kittnar et al. 2004). In the present study we also correlated electrocardiographic changes with the results of echocardiographic findings and spectral analysis of the heart rate variability.

\section{Methods}

\section{Screening procedure and diagnosis}

This study was conducted in the Center for Diabetes, Department of Internal Medicine University Hospital Motol in Prague in cooperation with the Institute of Physiology, $1^{\text {st }}$ Faculty of Medicine, Charles University in Prague. The local Ethics Committee, which follows the Helsinki Protocol has accepted the design of the presented study. All participants of the study have passed an oral glucose tolerance tests (oGTT), generating diagnostic indicators for GDM according to the Czech National Diabetes Data Group criteria. GDM was diagnosed in the 24-28th week of gestation using oGTT with $75 \mathrm{~g}$ glucose load, when fasting glucose in venous plasma was less than $7.0 \mathrm{mmol} / \mathrm{l}$. Women, whose fasting glucose was $7.0 \mathrm{mmol} / \mathrm{l}$ and more, did not have to go through the functional test as they were diagnosed by the fasting glucose level as overt diabetes in pregnancy. Plasma glucose samples were collected at fasting, as well as one and two hours after glucose load. The diagnosis of gestational diabetes was established if any of the test values was abnormal: if fasting plasma glucose exceeded $5.5 \mathrm{mmol} / \mathrm{l}$, one hour plasma glucose exceeded $8.8 \mathrm{mmol} / 1$ or two hours oGTT plasma glucose exceeded $7.7 \mathrm{mmol} / \mathrm{l}$. Those criteria were the only ones officially accepted by the authorities at the time when experimental work was done. It is important to note, that new screening criteria for GDM based on The HAPO study (2008) and International Association of Diabetes and Pregnancy Study Groups (IADPSG Consensus Panel 2010) recommendations have been accepted in the Czech Republic this year (the diagnosis of gestational diabetes is established when any of the following three $75 \mathrm{~g} \mathrm{2-h}$ OGTT thresholds are met or exceeded: fasting $5.1 \mathrm{mmol} / 1$, one hour $10 \mathrm{mmol} / 1$, two hours $8.5 \mathrm{mmol} / \mathrm{l}$ ).

35 women with GDM and 31 healthy pregnant women were enrolled in the study. Patients with a prior history of hypertension, preeclampsia, and chronic diseases were excluded from the study. However, patients with hypothyroidism on adequate replacement therapy were included. All patients with GDM were followed and assessed at our outpatient department bi-weekly from diagnosis until delivery. They received complex dietary counseling and in indicated cases insulin as well. Target glucose level in the treatment of GDM was a fasting blood glucose of less than $5.6 \mathrm{mmol} / \mathrm{l}$, and less than $6.7 \mathrm{mmol} / \mathrm{l} 2 \mathrm{~h}$ after the glucose load.

All examinations were performed in the 36th week of gestation. The anthropometrics and biometric measurements - height (in meters) was taken using a stadiometer and the patients were required to stand upright, but with the body and head touching the meter ruler (m). Weight (in kilograms) was taken using a standard weighing scale while patients were wearing light clothes with shoes taken off. Body mass index (BMI) was calculated using the following formula: BMI = body weight $(\mathrm{kg})$ / body height $\left(\mathrm{m}^{2}\right)$.

\section{Measurement}

The electrocardiogram (ECG), vectorcardiogram (VCG) and body surface isopotential, isointegral and isoarea maps (BSM) were registered altogether using the diagnostic system CARDIAG 112.2 (Kittnar and Stovicek 1993, Slavicek et al. 2001). 201 parameters of heart electrical field were registered in GDM patients and controls. Patient heart rate, duration of PQ, QRS, QT and QTc intervals were recorded and evaluated by 12 leads ECG. In the VCG evaluation, the Frank orthogonal lead system was used (Frank 1956). The depolarization, repolarization isopotential maps (DIPM, RIMP), isointegral depolarization and repolarization maps (DIIM, RIIM) and their maximum and minimum were recorded and evaluated by ECG body surface potential maps (BSM). Depolarization isoarea maps, their maximum and minimum in $\mu \mathrm{Vs}$ and repolarization areas and their maximum and minimum in $\mu \mathrm{Vs}$ were examined as well as isointegral minimum (Q-IIM), amplitude (IPMAM-Q) of Q wave as and QT duration in the chest electrodes. Myocardial activation time (ICHVAT in ms) was measured between the beginning of depolarization in an orthogonal lead and the $\mathrm{R}$ wave in the individual chest leads.

Transthoracic echocardiography, including pulse Doppler and tissue Doppler imaging (TDI) were performed using a Philips Sonos ${ }^{\circledR} 7500$ cardiac ultrasound unit (Philips Healthcare, Andover, MA, USA). Interventricular septal thickness (IST), posterior wall thickness (PWT), LV end diastolic diameter (LVEDD), LV end systolic diameter (LVESD), and left atrial 
diameter were determined. Relative wall thickness (RWT) was determined using $2 \mathrm{x}$ posterior wall thickness (PWT)/LVEDD. The LV ejection fraction was evaluated according to the Teicholz formula (Teichholz et al. 1976). Left ventricular mass (LVM) was calculated by the following equation following ASE (American Society of Echocardiography) convention (Devereux and Reichek 1977, Lang et al. 2005):

$$
\begin{aligned}
\operatorname{LV} \text { Mass }(\mathrm{g})= & 0.8\left\{1 . 0 4 \left[\left([\mathrm{LVEDD}+\mathrm{IST}+\mathrm{PWT}]^{3}-\right.\right.\right. \\
& \left.\left.\left.-\mathrm{LVEDD}^{3}\right)\right]\right\}+0.6
\end{aligned}
$$

Left ventricular mass index (LVMI) was determined as LVM/body surface area. Mitral inflow velocity was traced and the following variables of diastolic function were measured and evaluated: peak velocities of early (E) and late (A) transmitral flow, the ratio E/A, and deceleration time (DT). The peak velocities of early $\left(E^{\prime}\right)$ and late $\left(A^{\prime}\right)$ diastolic mitral annular motion (average of septal and lateral values) were determined from TDI recordings, and mitral $\mathrm{E} / \mathrm{E}^{\prime}$ and E'/A' ratios were calculated (Sohn et al. 1997).

HRV analysis was made by using VariaCardio TF4 device (Sima Media, Olomouc). Spectral analysis of RR intervals was performed by Fourier Transform algorithm, and the following frequency-domain HRV variables were obtained: low frequency (LF) component $(0.05-0.15 \mathrm{~Hz})$ and high-frequency (HF) component $(0.15-0.4 \mathrm{~Hz})$. Total spectral power and low frequency/high frequency ratio (LF/HF) were also calculated. All calculations were undertaken by measuring ECG recordings of RR intervals automatically, using the computer-aided examination and evaluation system.

\section{Statistical evaluation}

Statistical analyses and database management were performed using SAS (SAS Institute, Cary, NC). Results are expressed as the mean \pm standard deviation. The significance of differences in parameters was determined by Student's $t$-test for nonpaired samples and by chi-squared test on an appropriate basis. The correlation coefficient was obtained by the method of least squares, tests for normality by KolmogorovSmirnov tests. Simple correlations were performed using Pearson's or Spearman's correlation coefficient, where appropriate. We tested the significance level alpha of $5 \%$ $(\alpha=0.05)$.

\section{Results}

35 women with GDM and 31 healthy pregnant women were enrolled in the study. There was no significant difference between the groups in terms of weight, height, BMI, age, The average age of 35 women with GDM was $32 \pm 4$ years, compared to $30.3 \pm 4$ years (NS) in 31 healthy women. 17 patients with GDM were primigravidas, 18 women were in their second or third pregnancy. In the control group 21 were primigravidas and 10 controls in their second or third pregnancy. Women with GDM had significantly lower weight gain during gestation than controls $(p=0.05)$. Basic characteristics of the examined groups are shown in Table 1. Patients with GDM were divided into two subgroups: group treated with lifestyle changes and insulin-treated group; these two groups showed no statistically significant difference in basic anthropometrics and biometric parameters.

Table 1. Basic characteristics between GDM and non-GDM patients (mean values \pm standard deviations).

\begin{tabular}{llll}
\hline & GDM group $(\mathbf{n}=\mathbf{3 5})$ & Control group $(\mathbf{n = 3 1})$ & P value \\
\hline Mean age (years) & $32 \pm 4$ & $30.3 \pm 4.2$ & $\mathrm{NS}$ \\
Height $(\mathrm{cm})$ & $166 \pm 5.9$ & $168.3 \pm 7.4$ & $\mathrm{NS}$ \\
Weight $(\mathrm{kg})$ & $77.2 \pm 13.3$ & $77.1 \pm 13.5$ & $\mathrm{NS}$ \\
Weight gain in pregnancy $(\mathrm{kg})$ & $10 \pm 7.6$ & $13.1 \pm 3.7$ & 0.05 \\
BMI $\left(\mathrm{kg} / \mathrm{m}^{2}\right)$ & $28.2 \pm 3.8$ & $27.1 \pm 4.1$ & $\mathrm{NS}$ \\
Mean MAP $(\mathrm{mm} \mathrm{Hg})$ & $84 \pm 6.5$ & $87 \pm 8$ & $\mathrm{NS}$ \\
Mean heart rate & $84 \pm 10.4$ & $86 \pm 11$ & $\mathrm{NS}$ \\
\hline
\end{tabular}

MAP - mean arterial pressure 


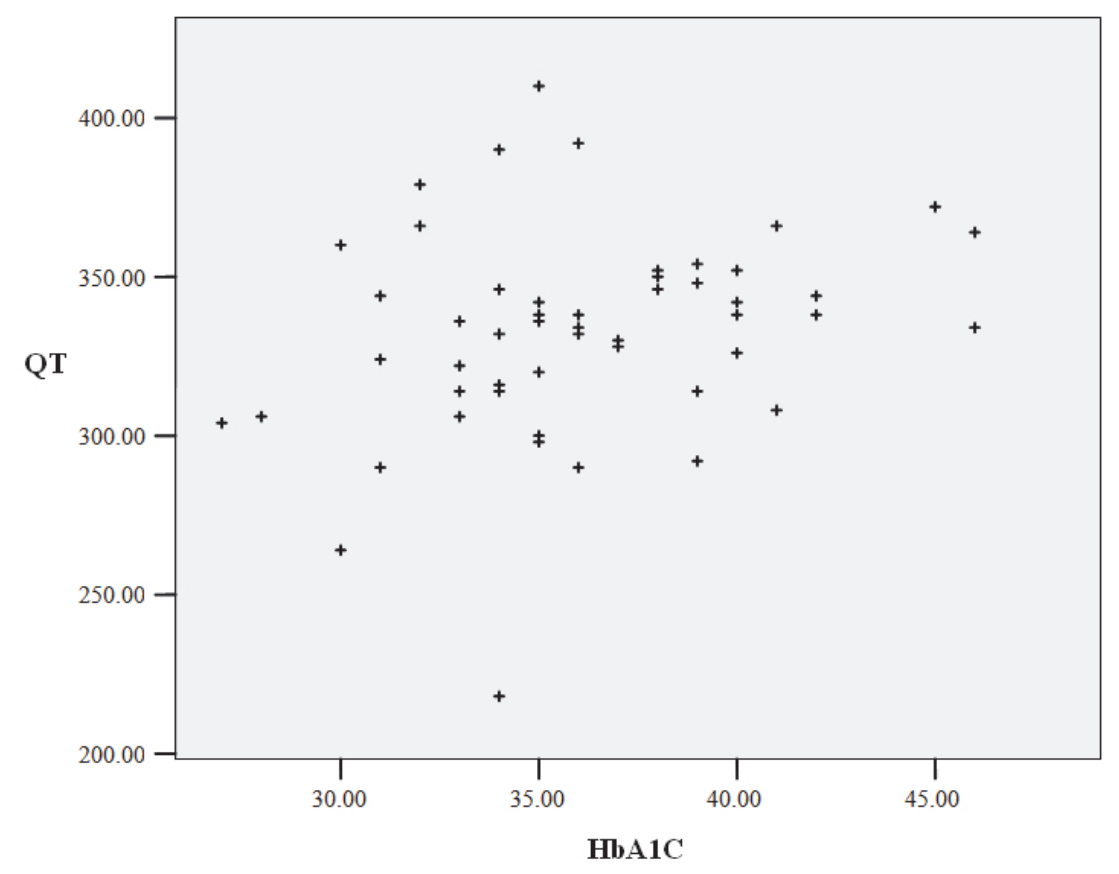

Fig. 1. Relation of $\mathrm{QT}$ and $\mathrm{HbA1C}$ in the whole cohort $(p=0.038)$.

Table 2. Comparison electrocardiographic parameters between GDM and control group.

\begin{tabular}{llll}
\hline & GDM group & Control group & p value \\
\hline QRS duration $(m s)$ & $83 \pm 15.7$ & $76 \pm 7$ & 0.03 \\
$I C H V A T$ max & $205.7 \pm 88.5$ & $262.85 \pm 91.6$ & 0.009 \\
$\max Q T$ & $400.4 \pm 46.3$ & $370 \pm 49.3$ & 0.005 \\
QTd & $128.8 \pm 14.4$ & $89 \pm 17$ & 0.01 \\
DIPM 30 min & $159.7 \pm 93.6$ & $225.7 \pm 75.6$ & 0.002 \\
\hline
\end{tabular}

Mean values \pm standard deviations. ICHVAT - myocardial activation time, DIPM - depolarization isopotential map in the $30^{\text {th }} \mathrm{ms}$

24 women with GDM were treated with diet modification, 4 with diet modification and conventional insulin regimen and 7 with diet modification and intensified insulin regimen. The average daily dose of insulin for patients with GDM treated with intensified insulin regimen at the time of examination was $15.7 \pm$ 5.2 units, in patients treated with conventional insulin regimen $7 \pm 2.9$ units. Fasting blood glucose in women with GDM was $5.0 \pm 0.5 \mathrm{mmol} / 1$ compared to $4.6 \pm$ $0.3 \mathrm{mmol} / \mathrm{l}$ in healthy pregnant women $(\mathrm{p}=0.002)$. HOMA index in GDM patients was $2.6 \pm 2.0$ compared to $1.7 \pm 1$ in control group ( $p=0.049$ ). In both groups, heart rate, systolic $\mathrm{BP}$, diastolic BP, MAP was of similar values.

ECG body surface mapping did not show statistically significant changes in depolarization and repolarization using isopotential (DIPM, RIPM), isointegral (DIIM, RIIM) or isoarea maps (DIAM and
RIAM) between the group of women with GDM and healthy pregnant controls. This is consistent with the results of spectral analysis of heart rate variability examinations. ECG mapping revealed significantly prolonged duration of QT interval in the group of patients with GDM in comparison to the control group $(p=0.01)$. Based on the results of ECG mapping an increased QT dispersion in patients with GDM was demonstrated. It was evaluated as the difference between the longest and shortest QT interval in any lead. The average QT dispersion $( \pm \mathrm{SD})$ in the control group was significantly lower $(89 \pm 17 \mathrm{~ms})$ than in women with GDM (128.8 \pm $14.4 \mathrm{~ms}, \mathrm{p}<0.01)$. The duration of QT interval was significantly longer in GDM subjects (400.4 \pm 46.3 vs. $370.1 \pm 49.3 \mathrm{~ms}, \mathrm{p}<0.01)$. Moreover, positive correlation between QT interval and HbA1C level has been found (Fig. 1). Pronounced differences were also found in the 
duration of QRS complex and myocardial activation time (ICHVAT). The duration of QRS complex was significantly shorter in non GDM than GDM group (76 \pm $7 \mathrm{~ms}$ vs. $82.9 \pm 15.7 \mathrm{~ms}, \mathrm{p}=0.05)$. Activation time of the ventricular myocardium in healthy pregnant women (262.8 $\pm 91.6 \mathrm{~ms})$ was longer than in women with GDM $(205.7 \pm 88.5 \mathrm{~ms}, \mathrm{p}<0.01)$. Important electrocardiographic parameters with statistically significant differences are summarized in Table 2. ICHVAT significantly correlated with the thickness of the interventricular septum and posterior wall diameter $(\mathrm{p}=0.01, \mathrm{p}=0.02)$, Figures 2,3 . The duration of the QRS complex in the GDM group further correlated with echocardiographic findings PWT, IST $(p=0.008$ and $p=0.004)$.

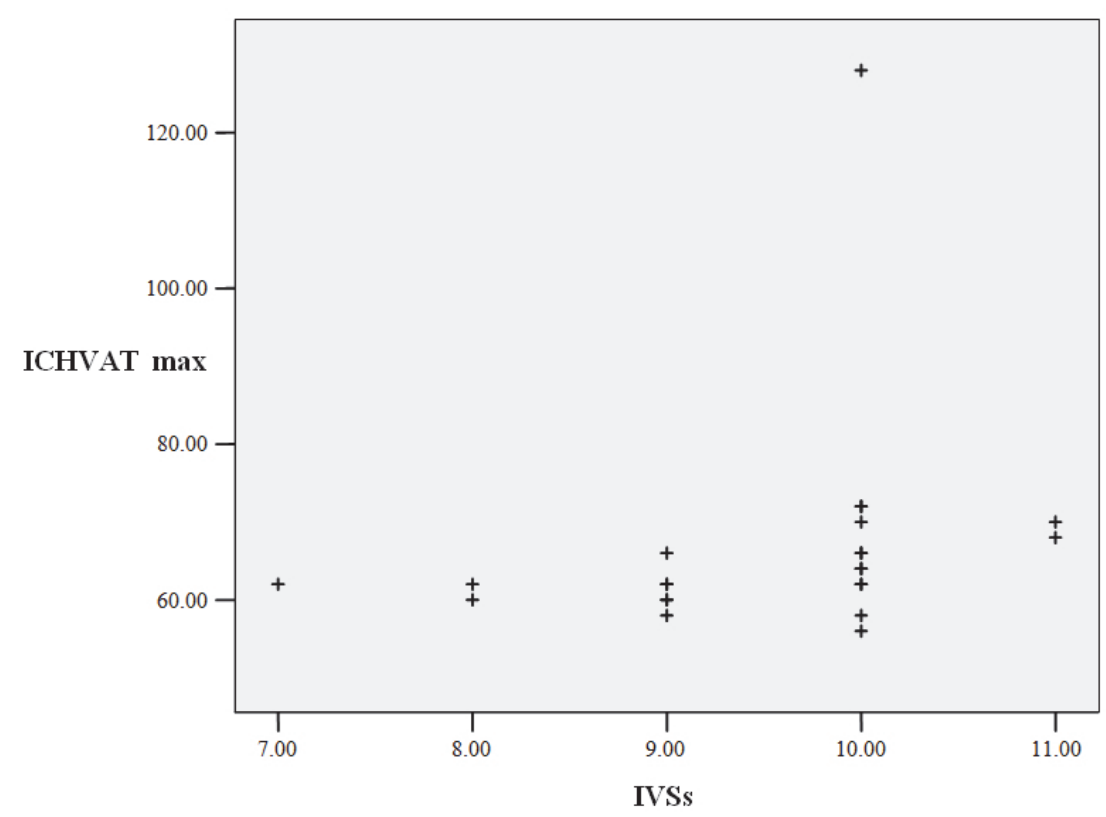

Fig. 2. Relation of ICHVAT max and IVSd in the GDM group $(p=0.011)$. (IVSd - Interventricular septum diameter, ICHVAT - Ventricular myocardial activation time)

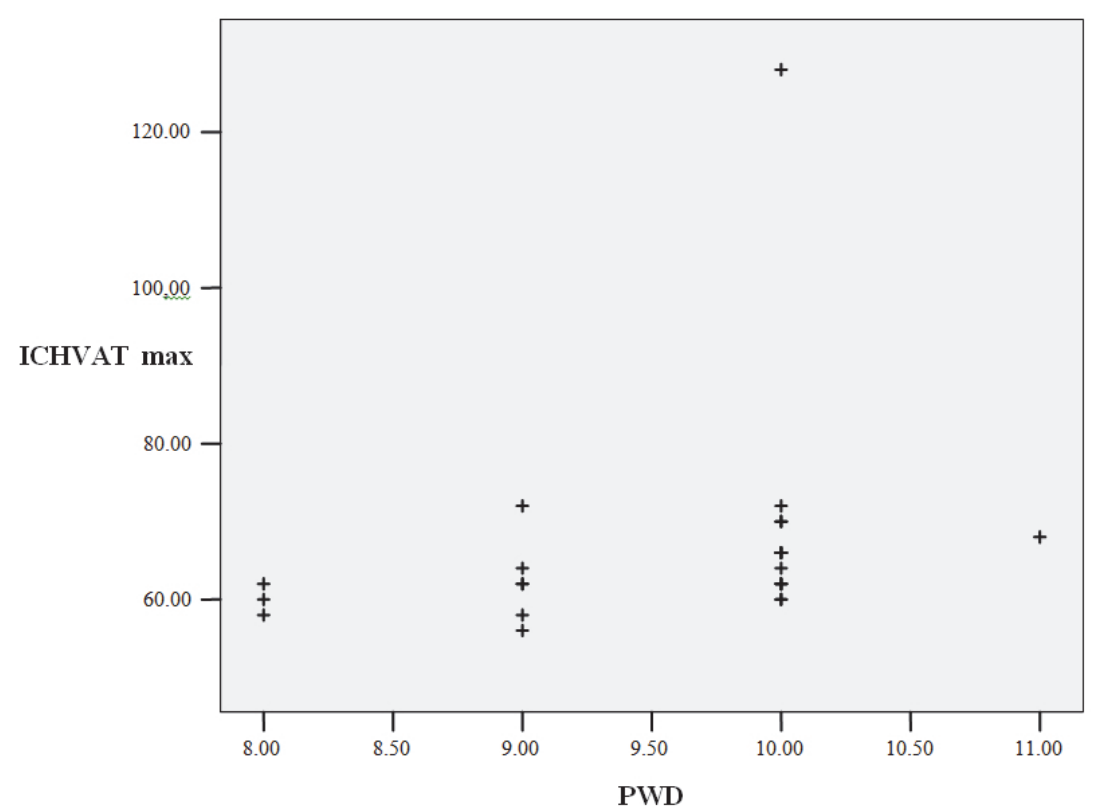

Fig. 3. Relation of ICHVAT max and PWD in the GDM group $(p=0.011)$. (PWD - left ventricular posterior wall diameter, ICHVAT - Ventricular myocardial activation time)

Echocardiographic results are presented in Table 3. Patients with GDM did not have detectable changes in terms of diastolic dysfunction comparing to controls. Nevertheless, patients with GDM had significantly larger interventricular septum diameter, posterior wall thickness and relative wall thickness ( $\mathrm{p}$ value $=0.04,<0.01$ and 0.01 , respectively).

Parasympathetic activity assessed by spectral power in high frequency (HF) for three consecutive time intervals was $151 \pm 155,230 \pm 343,212 \pm 280 \mathrm{~ms}^{2}$ in the 
control group, which was comparable to $234 \pm 341$, $170 \pm 271,216 \pm 277 \mathrm{~ms}^{2}$ (NS) in women with GDM. Sympathetic activity evaluated as a LF / HF ratio (low frequency / high frequency) in three consecutive intervals was $1.9 \pm 1.7,1.9 \pm 1.6,1.7 \pm 1.9$ in the control group, which was comparable to $2.1 \pm 1.7,3.6 \pm 3.9$ and $2.1 \pm 2.3$ (NS) in women with GDM. Total parasympathetic activity evaluated as the sum of all three intervals (HF1 + HF2 + HF3) was $632 \pm 511 \mathrm{~ms}^{2}$ in the control group and $621 \pm 790$ $\mathrm{ms}^{2}$ in GDM group (NS). Total sympathetic activity evaluated as the sum of LF / HF ratio in all three intervals $(\mathrm{LF} 1 / \mathrm{HF} 1+\mathrm{LF} 2 / \mathrm{HF} 2+\mathrm{LF} 3 / \mathrm{HF} 3)$ was $5.5 \pm 4.1$ in the control group versus $7.9 \pm 6.0$ in the group of women with GDM (NS).

Table 3. Doppler echocardiography parameters in patients with GDM and healthy pregnant subjects (mean values \pm standard deviations).

\begin{tabular}{llll}
\hline & GDM (n=35) & Control (n=31) & P value \\
\hline LVEDd $(\mathrm{mm})$ & $46.8 \pm 4.3$ & $47.6 \pm 4$ & 0.4 \\
LVESd $(\mathrm{mm})$ & $25 \pm 4$ & $22.7 \pm 8.8$ & 0.2 \\
IVSd $(\mathrm{mm})$ & $9.6 \pm 1$ & $9.1 \pm 0.8$ & 0.04 \\
PWd $(\mathrm{mm})$ & $9.6 \pm 0.8$ & $9 \pm 1$ & $<0.01$ \\
LV mass $(\mathrm{g})$ & $155.6 \pm 29$ & $147.3 \pm 27$ & 0.2 \\
LV mass index $\left(\mathrm{g} / \mathrm{m}^{2}\right)$ & $82 \pm 13$ & $78.5 \pm 11$ & 0.3 \\
RWT & $0.4 \pm 0.05$ & $0.38 \pm 0.03$ & 0.01 \\
EF & $65 \pm 4.9$ & $63.2 \pm 4.8$ & 0.16 \\
\hline
\end{tabular}

LVEDd - left ventricular end diastolic diameter, LVESd - left ventricular end systolic diameter, IVSd - intraventricular septal thickness, PWd - posterior wall thickness, LV - left ventricle, RWT - relative wall thickness, EF - ejection fraction of left ventricle

\section{Discussion}

In the previous study with ECG body surface mapping, several significant changes in depolarization and repolarization were detected in the patients with type 1 diabetes mellitus (Zdarska et al. 2007). The cardiac autonomic neuropathy impact on the electrocardiographic maps was shown in the following report (Palova et al. 2010).

Gestational diabetes mellitus (GDM) is defined as any degree of glucose intolerance with onset or first recognition during pregnancy (Metzger and Coustan 1998). GDM is associated with increased cardiovascular risk later in mother's life (Caballero 2003, Carpenter 2007, Davis et al. 1999). In the various recent studies, the pathological changes in $24 \mathrm{~h}$ blood pressure profile, echocardiography evaluation and heart rate variability were reported in women with GDM (Freire et al. 2006, Poyhonen-Alho et al. 2010, Soydinc et al. 2013). However, the intensity of glycemic control during the pregnancy was not sufficiently described there. Hence, the importance of optimal GDM compensation was not evaluated in those studies. It is possible that adequate compensation might have a major effect on the presence of the identified changes. In our study, all patients with gestational diabetes were adequately controlled in accordance to a predetermined protocol.

The aim of the current study was to find possible changes of electric heart field in GDM patients with comprehensive care, including their interpretation with the assistance of other noninvasive cardiologic examinations. It must be reminded, that several significant changes of the electrical heart field have already been detected in the late pregnancy: increased heart rate, shortening of $\mathrm{A}-\mathrm{V}$ conductance, prolongation of QTc interval and changes in the ventricular depolarization and repolarization patterns (Lechmanova et al. 2002).

Cardiovascular autonomic neuropathy (CAN) is the most studied form of DAN (diabetic autonomic neuropathy) and it's prevalence varies between cohorts of diabetic patients, due to differences in the methodology (O'Brien et al. 1986, Vinik and Ziegler 2007, Ziegler et al. 1992). Changes in spectral analysis of HRV, such as increased sympathetic activity and reduced parasympathetic activity of the autonomic vegetative system has already been described in the offspring of patients with DM type 2 (De Angelis et al. 2001, Laitinen et al. 1999) or pre-diabetic patients with insulin resistance (Lefrandt et al. 2000). One recent Finnish study 
(Heiskanen et al. 2010) showed that women with GDM and proper metabolic control compared with healthy pregnant women, did not have present significant changes in autonomic vegetative system, as it was previously assumed (Poyhonen-Alho et al. 2010). Similarly, our results of heart rate variability in patients with GDM were comparable to healthy control pregnant women. As it was mentioned, cardiac autonomy neuropathy is associated with the significant changes in depolarization and repolarization maps in patients with type 1 diabetes mellitus. Therefore, absence of any significant changes in depolarization and repolarization maps between optimally controlled patients with GDM and healthy controls were not surprising.

Previous work detected significantly higher average QT dispersion in women suffering from GDM when compared with physiological pregnancy (Medova et al. 2012). In addition to this, our BSM results also revealed significant prolongation of the QRS complex, shortening of the ventricular myocardial activation time (ICHVAT), prolongation of mean QT duration and similarly, increase of QT interval dispersion in women with GDM reported already in the previous observation. Duration of the QRS complex and ICHVAT significantly correlated with interventricular septum and posterior wall thickness in GDM group evaluated by echocardiography. The length of QTc interval correlated significantly with $\mathrm{HbA1C}$.

Despite of using predetermined protocol, fasting plasma glucose and HbAlc were significantly higher in GDM patients for whole period of pregnancy and might induce some morphological changes in myocardium. Moreover, the study showed no differences between patients with GDM and the control group regarding the BMI.

Diagnostic and screening criteria for gestational diabetes mellitus are still not internationally unified.
Recently, the International Association of Diabetes and Pregnancy Study Groups (IADPSG Consensus Panel 2010) recommended new screening criteria for GDM based on the HAPO study results. The new criteria have been accepted in the Czech Republic this year. The objective of the HAPO study was to clarify associations of levels of maternal glucose lower than those diagnostic of diabetes with perinatal outcome (The HAPO Study Cooperative Research Group 2008). It is important to mention, that this study did not primary occupy cardiovascular issues.

Using diagnostic criteria valid in the Czech Republic at the time when our work has been done showed us, that there is still certain involvement of cardiovascular system compared to controls and that probably the new screening criteria with lower diagnostic FPG thresholds are more appropriate to avoid it. On the other hand, it is necessary to remark that at the time study has started, the criteria that we used were the only ones officially accepted in the Czech Republic. Importantly, we consider that other similar studies with currently accepted criteria are needed to be done.

In summary, results of our research demonstrate that several significant abnormalities detected with ECG body surface mapping are still present in the patients with GDM despite their optimal metabolic control.

\section{Conflict of Interest}

There is no conflict of interest.

\section{Acknowledgements}

Supported by PRVOUK-P35/LF1/5 and SVV266503/2013. The authors wish to thank to Dr. Eva Medová and to Mrs. Tereza Vavríková for registration and evaluation of parameters of heart electric field, and to Mrs. Alena Dohnalová for the statistical measurements.

\section{References}

BELLAMY L, CASAS JP, HINGORANI AD, WILLIAMS D: Type 2 diabetes mellitus after gestational diabetes: a systematic review and meta-analysis. Lancet 373: 1773-1779, 2009.

CABALLERO AE: Endothelial dysfunction in obesity and insulin resistance: a road to diabetes and heart disease. Obes Res 11: 1278-1289, 2003.

CARPENTER MW: Gestational diabetes, pregnancy hypertension, and late vascular disease. Diabetes Care 30 (Suppl 2): S246-S250, 2007.

COWAN JC, YUSOFF K, MOORE M, AMOS PA, GOLD AE, BOURKE JP, TANSUPHASWADIKUL S, CAMPBELL RW: Importance of lead selection in QT interval measurement. Am J Cardiol 61: 83-87, 1988. 
DAVIS CL, GUTT M, LLABRE MM, MARKS JB, O'SULLIVAN MJ, POTTER JE, LANDEL JL, KUMAR M, SCHNEIDERMAN N, GELLMAN M, SKYLER JS: History of gestational diabetes, insulin resistance and coronary risk. J Diabetes Complications 13: 216-223, 1999.

De ANGELIS C, PERELli P, TREZZA R, CASAGRANDE M, BISELli R, PANNITTERI G, MARINO B, FARRACE S: Modified autonomic balance in offsprings of diabetics detected by spectral analysis of heart rate variability. Metabolism 50: 1270-1274, 2001.

DEVEREUX RB, REICHEK N: Echocardiographic determination of left ventricular mass in man. Anatomic validation of the method. Circulation 55: 613-618, 1977.

FEIG DS, ZINMAN B, WANG X, HUX JE: Risk of development of diabetes mellitus after diagnosis of gestational diabetes. CMAJ 179: 229-234, 2008.

FRANK E: An accurate, clinically practical system for spatial vectorcardiography. Circulation 13: 737-749, 1956.

FREIRE CM, NUNES M DOC, BARBOSA MM, LONGO JR, NOGUEIRA AI, DINIZ SS, MACHADO LJ, DE OLIVEIRA AR Jr: Gestational diabetes: a condition of early diastolic abnormalities in young women. $J \mathrm{Am}$ Soc Echocardiogr 19: 1251-1256, 2006.

HEISKANEN N, SAARELAINEN H, KARKKAINEN H, VALTONEN P, LYYRA-LAITINEN T, LAITINEN T, VANNINEN E, HEINONEN S: Gestational diabetic patients with adequate management have normal cardiovascular autonomic regulation during the third trimester of pregnancy and 3 months after delivery. J Diabetes Complications 24: 234-241, 2010.

IADPSG CONSENSUS PANEL: International Association of Diabetes and Pregnancy Study Groups recommendations on the diagnosis and classification of hyperglycemia in pregnancy. Diabetes Care 33: 676-682, 2010.

KIM C, NEWTON KM, KNOPP RH: Gestational diabetes and the incidence of type 2 diabetes: a systematic review. Diabetes Care 25: 1862-1868, 2002.

KITTNAR O, STOVICEK P: Contemporary body surface potential mapping in electrocardiology and its perspectives. Physiol Res 42: 141-143, 1993.

KITTNAR O, PACLT I, MLCEK M, SLAVICEK J, DOHNALOVA A, HAVRANEK S, BRIZMAN E, KITZLEROVA E, PISVEJCOVA K: QT dispersion and electrical heart field morphology in patients treated with dosulepin. Physiol Res 53: 379-386, 2004.

LAITINEN T, VAUHKONEN IK, NISKANEN LK, HARTIKAINEN JE, LANSIMIES EA, UUSITUPA M, LAAKSO M: Power spectral analysis of heart rate variability during hyperinsulinemia in nondiabetic offspring of type 2 diabetic patients: evidence for possible early autonomic dysfunction in insulin-resistant subjects. Diabetes 48: 1295-1299, 1999.

LANG RM, BIERIG M, DEVEREUX RB, FLACHSKAMPF FA, FOSTER E, PELLIKKA PA, PICARD MH, ROMAN MJ, SEWARD J, SHANEWISE JS, SOLOMON SD, SPENCER KT, SUTTON MS, STEWART WJ: Recommendations for chamber quantification: a report from the American Society of Echocardiography's Guidelines and Standards Committee and the Chamber Quantification Writing Group, developed in conjunction with the European Association of Echocardiography, a branch of the European Society of Cardiology. J Am Soc Echocardiogr 18: 1440-1463, 2005.

LECHMANOVA M, PARIZEK A, HALASKA M, SLAVICEK J, KITTNAR O: Changes of the electrical heart field and hemodynamic parameters in the 34th to 40th weeks of pregnancy and after delivery. Arch Gynecol Obstet 266: 145-151, 2002.

LEFRANDT JD, MULDER MC, BOSMA E, SMIT AJ, HOOGENBERG K: Inverse relationship between blood glucose and autonomic function in healthy subjects. Diabetes Care 23: 1862-1864, 2000.

MEDOVA E, FIALOVA E, MLCEK M, SLAVICEK J, DOHNALOVA A, CHARVAT J, ZAKOVICOVA E, KITTNAR O: QT dispersion and electrocardiographic changes in women with gestational diabetes mellitus. Physiol Res 61 (Suppl 2): S49-S55, 2012.

METZGER BE, COUSTAN DR: Summary and recommendations of the Fourth International Workshop-Conference on Gestational Diabetes Mellitus. The Organizing Committee. Diabetes Care 21 (Suppl 2): B161-B167, 1998.

O'BRIEN IA, O'HARE JP, LEWIN IG, CORRALL RJ: The prevalence of autonomic neuropathy in insulin-dependent diabetes mellitus: a controlled study based on heart rate variability. Q J Med 61: 957-967, 1986. 
PALOVA S, SZABO K, CHARVAT J, SLAVICEK J, MEDOVA E, MLCEK M, KITTNAR O: ECG body surface mapping changes in type 1 diabetic patients with and without autonomic neuropathy. Physiol Res 59: 203-209, 2010.

POYHONEN-ALHO M, VIITASALO M, NICHOLLS MG, LINDSTROM BM, VAANANEN H, KAAJA R: Imbalance of the autonomic nervous system at night in women with gestational diabetes. Diabet Med 27: 988994, 2010.

SLAVICEK J, KITTNAR O, NOVAK V, TREFNY Z, HORACEK BM: ECG body surface isointegral and isoarea maps (BSM) in 30 and 60-years-old healthy humans. Sb Lek 102: 369-374, 2001.

SOHN DW, CHAI IH, LEE DJ, KIM HC, KIM HS, OH BH, LEE MM, PARK YB, CHOI YS, SEO JD, LEE YW: Assessment of mitral annulus velocity by Doppler tissue imaging in the evaluation of left ventricular diastolic function. J Am Coll Cardiol 30: 474-480, 1997.

SOYDINC HE, DAVUTOGLU V, SAK ME, ERCAN S, EVSEN MS, KAYA H, OYLUMLU M, BUYUKASLAN H, SARI I: Circadian variation of blood pressure is impaired in normotensive pregnant women with gestational diabetes mellitus. Clin Exp Hypertens 35: 128-133, 2013.

SULLIVAN SD, UMANS JG, RATNER R: Gestational diabetes: implications for cardiovascular health. Curr Diab Rep 12: 43-52, 2012.

TEICHHOLZ LE, KREULEN T, HERMAN MV, GORLIN R: Problems in echocardiographic volume determinations: echocardiographic-angiographic correlations in the presence of absence of asynergy. Am J Cardiol 37: 7-11, 1976.

THE HAPO STUDY COOPERATIVE RESEARCH GROUP: Hyperglycemia and adverse pregnancy outcomes. N Engl J Med 358: 1991-2002, 2008.

VINIK AI, ZIEGLER D: Diabetic cardiovascular autonomic neuropathy. Circulation 115: 387-397, 2007.

ZDARSKA D, PELISKOVA P, CHARVAT J, SLAVICEK J, MLCEK M, MEDOVA E, KITTNAR O: ECG body surface mapping (BSM) in type 1 diabetic patients. Physiol Res 56: 403-410, 2007.

ZIEGLER D, GRIES FA, SPULER M, LESSMANN F: The epidemiology of diabetic neuropathy. Diabetic Cardiovascular Autonomic Neuropathy Multicenter Study Group. J Diabetes Complications 6: 49-57, 1992. 